\title{
Letter to the Editor Regarding "Assessment of Retinal Nerve Fiber Layer Thickness in Non-Diabetic Obese Children and Adolescents"
}

\author{
(D) Ömer Karti \\ University of Health Sciences, Bozyaka Training and Research Hospital, Clinic of Ophthalmology, Izmir, Turkey
}

\section{To the Editor,}

I read the manuscript entitled "Assessment of Retinal Nerve Fiber Layer Thickness in Non-Diabetic Obese Children and Adolescents" recently published online by Ozen et al (1) in the J Clin Res Pediatr Endocrinol with great interest. I would like to thank Ozen et al (1) for their comments on our publication entitled "The assessment of peripapillary retinal nerve fiber layer and macular ganglion cell layer changes in obese children: a cross sectional study using optical coherence tomography" (2). I would like to clarify some of the misunderstandings raised by Ozen et al (1). They said that our manuscript included patients with high refractive status (up to $5 \mathrm{D})$ and that this situation could have affected retinal nerve fiber layer (RNFL) values by optical coherence tomography (OCT). However, in our study, both the study group and the control group had rather low refraction values. Our study demonstrated that spherical equivalent was $-0.04 \pm 0.61 \mathrm{D}$ in the obese group and $-0.05 \pm 0.53$ in the non-obese group. Although not mentioned in the paper, patients' spherical equivalents ranged from +2.0 to $-1.5 \mathrm{D}$. We completely agree with the authors that the presence of a refraction error can cause inaccurate measurement of OCT and RNFL values. The measurement errors of OCT parameters due to differences in axial length or refractive error causing ocular magnification effects have been documented by previous studies $(3,4,5)$. OCT scans are typically angular. Hence, a 20 degree projection on a longer eye covers a larger area than on a hyperopic eye. The difference in scanned region (magnification), and the path used to quantify thickness is what causes differences in thickness versus refractive error or axial length. The transverse mirror in OCT is calibrated for an axial length of 24.46 $\mathrm{mm}$. Inter-individual differences in axial length which vary from $24.46 \mathrm{~mm}$ would result in magnification errors in the measurements made on OCT $(3,5,6)$. Therefore, to remove the effect of ocular magnification, the clinicians have to adjust the RNFL results using Littmann's method $(3,4,5,6,7)$. In this regard, the data present actual RNFL thickness in high refractive error.

Keywords: Obese children, optical coherence tomography, retinal nerve fiber layer

\section{Ethics}

Peer-review: Internally peer-reviewed.

Financial Disclosure: The author declared that this study received no financial support.

\section{References}

1. Ozen B, Ozturk H, Catlı G, Dundar B. An assessment of retinal nerve fiber layer thickness in non-diabetic obese children and adolescents. J Clin Res Pediatr Endocrinol 2017.

2. Karti O, Nalbantoglu O, Abali S, Ayhan Z, Tunc S, Kusbeci T, Ozkan B. Retinal ganglion cell loss in children with type 1 diabetes mellitus without diabetic retinopathy. Ophthalmic Surg Lasers Imaging Retina 2017;48:473-477.

3. Wang XY, Huynh SC, Burlutsky G, Ip J, Stapleton F, Mitchell P. Reproducibility of and effect of magnification on optical coherence tomography measurements in children. Am J Ophthalmol 2007;143:484-488.

4. Tan JC, Poinoosawmy D, Fitzke FW, Hitchings RA. Magnification changes in scanning laser tomography. J Glaucoma 2004;13:137-141.

5. Odell D, Dubis AM, Lever JF, Stepien KE, Carroll J. Assessing errors inherent in OCT-derived macular thickness maps. J Ophthalmol 2011;2011:692574

6. Wagner-Schuman M, Dubis AM, Nordgren RN, Lei Y, Odell D, Chiao H, Weh E, Fischer W, Sulai Y, Dubra A, Carroll J. Race- and sex-related differences in retinal thickness and foveal pit morphology. Invest Ophthalmol Vis Sci 2011;52:625-634.

7. Bennett AG, Rudnicka AR, Edgar DF. Improvements on Littmann's method of determining the size of retinal features by fundus photography. Graefes Arch Clin Exp Ophthalmol 1994;232:361-367. 